\title{
OS SISTEMAS DE SANEAMENTO ENQUANTO TECNOLOGIAS EM DISPUTAS: O TOUT-À-L'ÉGOUT EM BELO HORIZONTE (1893 - 1902)
}

The SewEr Systems As A Technologies In Dispute: The Tout-ÀL'Égout In Belo Horizonte, Brazil (1893 - 1902)

\author{
Diogo Jorge Oliveira \\ Universidade Federal de Minas Gerais \\ oliveiradjs@gmail.com
}

Wallace Carrieri de Paula Andrade

Universidade Federal de Minas Gerais

andradewcp@yahoo.com.br

\section{Resumo}

O presente trabalho pretende evidenciar as disputas tecnológicas, principalmente ao longo do século XIX, referentes aos sistemas de esgotamento sanitário que foram planejados e implementados na realidade urbana prematura de Belo Horizonte. A pesquisa partiu do método crítico para buscar compreender os debates acerca do uso das tecnologias dos sistemas de saneamento criados na modernidade e propostos para a Nova Capital de Minas. Um enfoque específico será dado ao conflito teóricopolítico entre os defensores e opositores do tout-à-l'égout, ou Sistema Unitário, a partir da realidade belorizontina ao fim do século XIX.

Palavras-chave:

Sistema de Esgoto, Belo Horizonte, Tecnologia, Tout-à-l'égout.

\section{Abstract}

This present paper intends to emphasize the technological disputes privately those which has occurred along the XIX century that are related to sewage systems that have been planned and implemented in premature urban reality of Belo Horizonte. The research started from the critical method aiming to comprehend debates about the use of technologies of sanitation systems which were created in the modernity and proposed to the New Capital of Minas Gerais. An specific focus will be given to the theoretical political conflict between defenders and opponents of tout-à-l'égout or the Unitary System, from the belohorizontina reality in the late of the XIX century.

\section{Keywords}




\section{Introdução}

Lidar com as águas indesejadas, produzidas por uma coletividade urbana sempre foi um problema para os habitantes e governantes das cidades. Se na Antiguidade foram adotadas técnicas rudimentares e simples, nas cidades modernas e contemporâneas a complexidade de questões envolvidas exigiu e exige soluções mais elaboradas. A tecnologia, como aplicação de conhecimentos (científicos ou não) à problemas concretos, acompanhou a complexidade dessas questões e também se desenvolveu, gerando soluções compatíveis com as possibilidades e paradigmas existentes em sua época.

Não é segredo dizer que o século XIXexistiam grandes cidades e capitais na Europaque possuíam o hábito de lançar as excretas pelas ruas. Se a Roma Antiga possuía um engenhoso sistema de fornecimento d'água (inclusive para limpeza pessoal) e de latrinas públicas (RESENDE; HELLER, 2008, p. 35), percebe-se na Idade Média certo esquecimento dessa tecnologia de saneamento e o exercício da prática de lançar "fezes, urinas e águas servidas em vias públicas" (RESENDE; HELLER, 2008, p. 36). Esse hábito "não-higiênico" acompanhará os europeus nos próximos séculos tanto em suas colônias (no Brasil, por exemplo), quanto nas próprias cidades das metrópoles.

No Brasil, até os fins do séc. XIX, muito pouco se havia feito quanto ao saneamento básico público. No plano privado, aqueles que pertenciam a classes mais abastadas se livravam de suas excreções higiênicas por meio dos "tigres", termo que denominava tanto o objeto para realizar as necessidades fisiológicas quanto o escravo que lançava as sujeiras contidas nesse objeto nos cursos d'águas. Acreditou-se até que "a facilidade em dispor de tigres tenha retardado a instalação de sistemas de esgotamento sanitário" em algumas cidades (RESENDE; HELLER, 2008, p. 125). Já emCastro e Amaro (2007) encontram-se textos que evidenciam outras soluções individuais ou coletivas para lidar com os dejetos, como por exemplo o lançando-os nas calçadas em épocas de chuvas,em "canais que passavam por debaixo das casas para escoamento das águas jogadas nos pátios", e em sistemas que seriam os precursores da fossa. Em geral, no plano público até então, havia se criado alguns sistemas de drenagens em áreas alagadas, inspeções em portos, criação de alguns órgãos de inspeção sanitária e uma curiosa lei "que tornava obrigatório o uso da 
expressão 'Água Vai!' antesdo lançamento de dejetos pelas janelas, para avisar aos transeuntes" nas cidades de Recife e Rio de Janeiro (RESENDE; HELLER, 2008, p. 105).

A ausência do Estado brasileiro na questão sanitária fez com que, em meadosdo século XIX, surgissem serviços de iniciativa privada que suprissem a demanda por sistemas de esgotamento. Assim, na década de 1850 a cidade do Rio de Janeiro passa a ser a primeira capital brasileira e uma das primeiras do mundo a possuir um sistema de esgoto, a partir da concessão de serviços sanitários à empresa inglesaCity ${ }^{1}$ (RESENDE; HELLER, 2008, p. 127). Já em Ouro Preto, capital das Minas Gerais e bem menor em tamanho do que a capital Imperial, algumas soluções locais tentavam remediar o problema sanitário. Castro e Amaro notam, em pesquisas documentais, que na cidade foram criados dispositivos práticos para que o povo se desfizesse de seus dejetos de forma mais "higiênica". E isso vai desde uma lei de 1796 que "se impõe contra a prática do 'tout-à-la-rue"2, exigindo dos moradores que limpassem as testadas de suas residências e proibindo-os de lançar sujeira nas ruas", até a colocação de "bueiros de seção quadrada, constituídos de lajes para escoamento de águas servidas e pluviais" (CASTRO; AMARO, 2007, s.p.). Nos fins do séc. XIX, é visível várias tentativas e execuções de projetos em Ouro Preto que tinham por objetivo melhorar a cidade para tentar reverter a mudança da capital para outra localidade.

\section{Engenhando o esgoto}

Os projetos de implementação ou modernização de tecnologias de esgotamento sanitário no Brasil sofrerão grande influência das tecnologias e estudos desenvolvidos no Velho Continente. Quando os ingleses, por meio da City, implementam um sistema de esgoto no Rio de Janeiro, não aplicam só redes de canais e tubulações para escoamento de dejetos, mas outras possibilidades de existência, novos hábitos e nova moral. Conforme apontam Castro e Amaro

A influência dos ingleses foi fundamental para a implantação de novos hábitos
higiênicos no Brasil. Com costumes mais apurados do que os franceses e
outros europeus, eles exerceram, através de sua presença marcante aqui no
século XIX, uma pressão para a instalação de melhorias a nível urbano, como
a instalação das estações de tratamento de esgoto, e ao nível dos interiores

\footnotetext{
${ }^{1}$ Sigla de The Rio de Janeiro City ImprovementsCompanyLimited.

2 "Tudo na rua", ou seja, os dejetos são lançados nas ruas sem nenhum cuidado.

URBANA, V.6, no 8, jun.2014 - Dossiê: Cidade e Habitação na América Latina - CIEC/UNICAMP
} 
da habitação, como a introdução dos W.C. e dos lavabos próximos à sala de refeições (CASTRO; AMARO, 2007, s.p.).

E essa mudança de valores e significados não acontecia apenas nos países periféricos. Na Inglaterra, França e outras nações europeias estavam ocorrendo uma radicalidade nas transformações de hábitos e sentidos sob a orquestração da burguesia, da ciência e das revoluções (industriais e políticas). Até o séc. XIX, os dejetos eram jogados nas vias ou, quando muito, canalizados e lançados nos cursos d'águas. Isso tornou as cidades europeias, já densas e poluídas (principalmente em consequência darevolução industrial), locais propícios para a propagação de doenças e epidemias. Não tardou muito para que uma epidemia de cólera dizimasse milhares de vidas europeias e forçasse os governos a tomarem medidas quanto aos esgotos. Em meados dos Oitocentos, engenheiros e cientistas promovem reformas radicais na área do saneamento, e propõe a separação das águas potáveis das águas servidas. E mais, criam um sistema unitário de esgotos onde seriam lançadas as águas usadas, dejetos das latrinas, dejetos industriais e águas pluviais em um mesmo canal. Esse sistema unitário ficou conhecido sob vários nomes: Sistema Unitário, Sistema de Esgotos GeraiseTout-à-l'égout ("tudo ao esgoto").

O Sistema Unitário possuía características bem específicas: é um sistema que reunia em uma mesma canalização as águas despejadas das latrinas, as águas servidas, águas dos edifícios públicos e comércio, despejos industriais, águas pluviais e aquelas provenientes de infiltrações. A tecnologia do tout-à-l'égout exigia grandes galerias de alguns metros de diâmetro (em Paris as maiores chegaram a ter 6 metros de diâmetro), onde seriam despejados líquidos carregados de canalizações menores. Contudo, se os ingleses de Londres foram aperfeiçoando sua tecnologia de esgotamento sanitário, os franceses - sobretudo de Paris - só foram tornar oficial a sua versão dotout-à-l'égout no fim do século XIX.Vale lembrar que essa tecnologia, mesmo apropriada especificamente para cidades do clima do noroeste europeu, décadas depois passou a ser criticada pelos ingleses, que viam nos grandes condutos um "desacerto sanitário" (MINAS GERAES, 1893, p.18).

Um autor que retrata essas mudanças de hábito e cultura em Pariscom rigor e criatividade é Corbin(1987). Esse autor traz diversas reflexões sobre como uma das mais destacadas capitais do séc. XIX (se não a principal) não conseguia resolver a questão dos esgotos sanitários. E faz isso através de uma história do olfato, dos cheiros e aromas (nem sempre agradáveis) daquela sociedade em transformação.Para Corbin, essa cidade demorou pela adoção efetiva do tout-à-l'égout por conta de um complexo debate onde "uma confluência de interesses estava em jogo contra a sua 
adoção" (1987, p. 155). Em Paris alguns ainda insistiam na prática de lançar excrementos pelas janelas, enquanto outros voltavam a utilizar fossas ${ }^{3}$ (secas ou não). Tais sujeiras, porém, não apenas fediam ou traziam doenças para a população, como também já movimentavam a indústria da imundície: eram transformadas em matérias-primas da indústria química e da produção de adubo. A coleta de lamas de excrementos das ruas, bem como as limpezas de fossas traziam bons lucros para pessoas e empresas que lidavam com esse serviço.

Essa "produção de matéria-prima imunda" não era só estimulada por uma preguiça social ou uma falta de cultura de uma fatia da sociedade ("os pobres" ou "os moradores das periferias", etc.), mas era um traço cultural secular compartilhado por aquela sociedade: "o despejo de excrementos sobre os montes de imundícies, isto é, nas calçadas, continua sendo uma prática corrente, mesmo entre os burgueses" (CORBIN, 1987, 224). Nessa época, em Paris, "vencer a sujeira dos 'comuns' e drenar as imundícias dos terreiros impõe-se como os mais urgentes dentre os imperativos" (CORBIN, 1987, p. 204). As latrinas públicas que existiam há séculos vão sendo abolidas, e o costume de familiarizar (ou seja, levar para dentro da família) o cuidado dos excrementos faz com que a latrina pública se torne privada. O banheiro vai aos poucos se tornado um cômodo da casa. Mas a resistência ao uso da água, e a lenta condução das águas sujas, fazem com que, durante décadas, as mudanças francesas fiquem na espacialidade doméstica (CORBIN, 1987, p. 222). Já na Inglaterra, o imperativo do uso da água corrente vai se tornando cada vez mais incorporado pelos habitantes ao longo dos Oitocentos, e o "armário com água" - water-closet - vai se tornando comum. Fazer circular as águas sujas impediriam os odores e doenças: essa era a lógica inglesa.

Será só no fim desse imundo século XIX, mais especificadamente na década de 80 , que as autoridades parisienses, em meio a um odor insuportável que pairava pela cidade, resolvem encarar a questão do esgoto na Cidade-luz. Uma comissão municipal - Comissão de Saneamento de Paris - inicia uma série de ações que vão ter como pressuposto a fluidez da água, sendo que nesse momento "a água desempenha aqui o papel de agente de limpeza, não de diluição" (CORBIN, 1987, p. 286), e "arrastado pela correnteza dos esgotos, o excremento perde sua nocividade" (p. 287). Toda uma tecnologia é criada a partir dos conhecimentos, materiais, técnicas e experiências que já se tinha notícia, e é apropriada por meio do seguinte projeto dessa Comissão:

\footnotetext{
${ }^{3}$ As novas casas construídas em meados do séc. XIX em Paris tinham como progresso as fossas sépticas, algo que "em Paris era condenada há mais de um século" (CORBIN, 1987, 224).
} 
As dejeções seriam recebidas, à saída dos gabinetes, em canos [...]. Esses condutos ligados entre si levariam para longe da cidade as matérias da limpeza das fossas, para um local onde as usinas instaladas se reuniriam para operar as transformações necessárias nessas matérias. (CORBIN, 1987, p. 286)

Enquanto na França há esse despertar para a circulação líquida e para as possibilidades dos esgotos gerais (sendo o tout-à-l'égout se tornado obrigatório apenas em 1894), na Inglaterra, como nos Estados Unidos, a questão não é mais discutir os méritos e os inconvenientes do Sistema Unitário, até porque já se sabia que esse sistema estava sendo muito dispendioso, "mas antes saber se o separate system [Sistema Separador], isto é, se a instalação de uma rede dupla para águas pluviais e para águas servidas não seria imperativa" (CORBIN, 1987, p. 287).

Em artigos ingleses e franceses de 1894 e 1895 encontram-se calorosas discussões a respeito do tout-à-l'egout. Alguns franceses tecem elogios ao sistema não pelo fato de retirar os esgotos da cidade, mas por reduzir o lançamento (à época) as águas sujas nos cursos d'águas, principalmente no rio Seine. Por isso, em um artigo, diz-se "Tout-à-l'égout, Rien-à-la-Seine" (tudo ao esgoto, nada no rio Seine), enfatizando o ganho "ambiental" da empreitada. Contudo, o destino dos esgotos, agora canalizados e bem líquidos, não era apenas as usinas químicas, mas para os champs d'épandages ("campos de depuração", como ficaram conhecidos no Brasil), que se situavam ao norte do Seine.

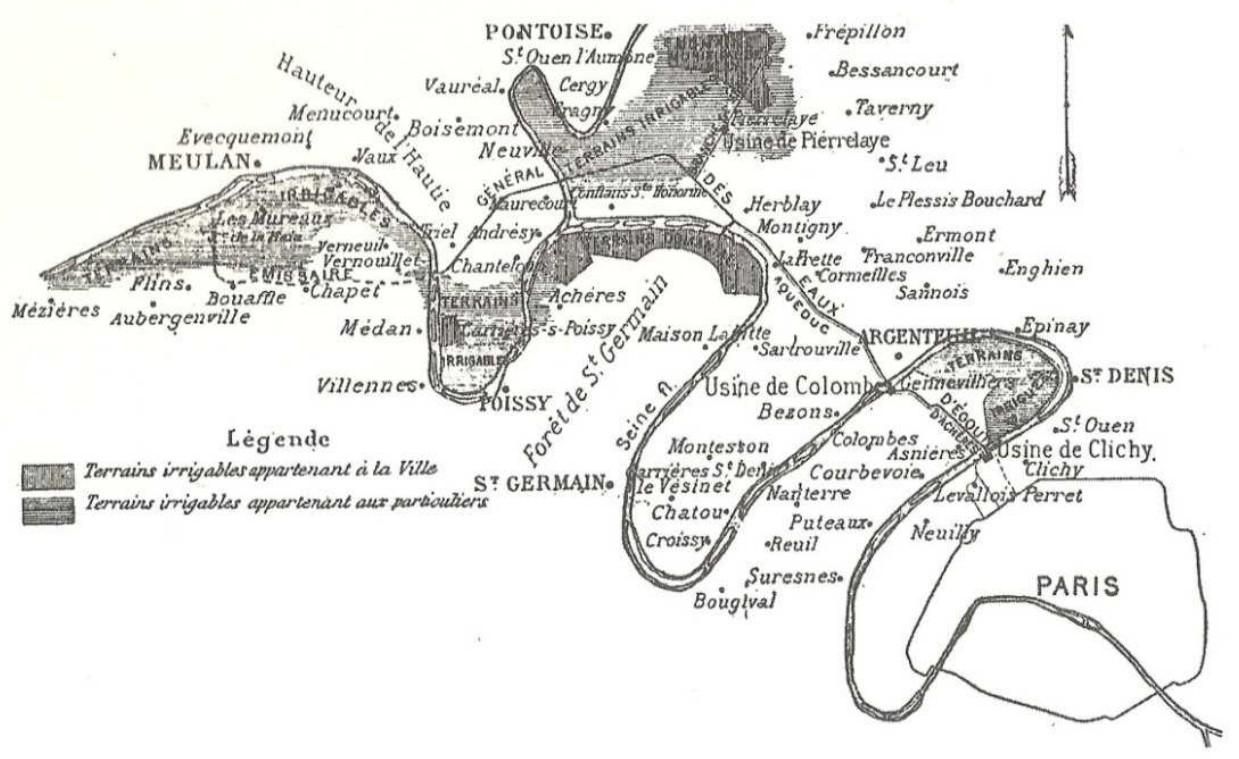

Figura 01 - Coletores de esgotos e terrenos de depuração próximos a Paris. Fonte: BECHMANN, 1899 
Nessas imensas áreas de depuração, procurou-se também preparar terras para cultivo de alimentos ou outras plantas. O mapa acima revela que a área somada das terras irrigáveis pertencentes ao governo e a particulares é extensa e aproximase da área da cidade de Paris. Isso se deve a estudos científicos que criaram parâmetros para os tamanhos de áreas irrigáveis por esgotos destinadas ao cultivo ou para outros fins. É importante ressaltar isso, poiso saneamento das cidades, no que tange à questão do esgoto, possui duas dimensões distintas, porém complementares: a coleta/adução e a destinação/tratamento. A escolha da localidade para sediar a futura capital mineira, e a implementação de uma tecnologia relacionada à coleta/destinação das águas usadas na nova capital, pautarão, a princípio, por essas duas dimensões.

\section{Um horizonte belo e esgotado?}

Sonho há muito desejado, foi apenas com o fim do Império e nascimento da República, que uma Nova Capital pode ser concretizada. A transferência da capital das Minas Gerais para um lugar mais centralizado geopoliticamente, um terreno menos acidentado (que Ouro Preto) e que garantisse a expansão da urbe do segundo estado mais rico e poderoso do país, motivou durante décadas essa antiga aspiração mineira. As turbulências político-sociais geradas pelo fim dos Oitocentos, principalmente a Abolição e a proclamação da República, e o aumento da capacidade de arrecadação (devido ao caráter liberal da Constituição de 1891), atrelada às altas divisas geradas pela produção do café nesse período (RESENDE; HELLER, 2008, p. 131) serão apropriadas e catalisadas por uma elite política e uma nascente elite econômica (ligada ao café) que efetivarão, em pouco tempo, a mudança da capital.

Um ano após a Constituição Mineira apontar para a mudança da capital, o então Presidente do Estado Affonso Penna criou meios para que fosse criada uma Comissão encarregada de estudar as possíveis localidades mineiras que poderiam vir a receber a sede do estado. Essa comissão passou a se chamar: Commissão d'Estudo das Localidades Indicadas para a Nova Capital' . Chefiada pelo renomado engenheiro Aarão Reis, da Escola Politéchnica do Rio de Janeiro, era composta ${ }^{5}$ de cinco

\footnotetext{
${ }^{4}$ Os trechos e expressões retiradas dos textos e arquivos históricos serão citados com a mesma escrita encontrada no original. Não serão feitas correções ortográficas, gramaticais ou de outro tipo.

${ }^{5}$ Os engenheiros eram José de Carvalho Almeida (designado para estudar Varzea do Marçal), Samuel Gomes Almeida (designado para estudar BelloHorisonte), Luiz Martinho de Moraes (designado para estudar Barbacena), Eugênio B. Raja Gabaglia (designado para estudar Juiz de Fora) e Manoel da Silva Couto (designado para estudar Paraúna); o médico-higienista era José Ricardo Pires d’Almeida.
} 
engenheiros, um médico-higienista e técnicos de apoio. Cada engenheiro tinha a incumbência de estudar, durante alguns meses de 1893, uma das localidades pretendidas, a saber: Várzea do Marçal (pertencente a S.J. D’El Rey), BelloHorisonte, Barbacena, Juiz de Fora, Paraúna (próximo a Diamantina); e ao final dos estudos compor um relatório para ser entregue ao chefe da comissão. Já o médico Pires $\mathrm{d}^{\prime}$ Almeida percorreria todas as localidades $^{6}$, analisando as condições higiênicas e de salubridade, condições essas de suma importância naquele contexto, produzindo também um relatório que fora entregue a Aarão Reis. Esse chefe então tomou esses relatórios, reuniu-os em um grande relatório e compôs uma síntese propositiva, onde emitia uma análise de cada relatório em particular e uma avaliação global sobre a(s) melhor(es) localidade(s). O resultado foi o Relatório da Commissão d'Estudo das Localidades Indicadas para a Nova Capital, que traz informações sintéticas e aprofundadas de cada localidade, referentes à várias temáticas, como por exemplo: condições naturais de salubridade, captação e abastecimento de água, drenagem e esgotamento, facilidade de edificação e construção, transporte, etc.

No item referente ao esgotamento, buscou-se estudar o "esgôto das matérias e águas servidas e pluviais e drenagem do solo, atendendo ao systema que melhor se preste ao saneamento interno e externo da futura cidade" (MINAS GERAES, 1893, p. 15). Esse saneamento interno se referia à canalização e adução das águas imundas e usadas dentro da cidade planejada para 200 mil habitantes, enquanto que o saneamento externo se referia à destinação desse esgoto coletado. Além disso, essa comissão deveria estudar também a localidade pensando no planejamento em curto prazo, ou seja, para uma população inicial de 30 mil habitantes. E o item referente às despesas deixa claro que se deveria preocupar em gastos mínimos na "instalação de um systema aperfeiçoado de esgôto na futura cidade, que possa funcionar regularmente, emquanto a população não exceder o limite indicado [de 30 mil habitantes]" (MINAS GERAES, 1893, p.15).

A avaliação e a síntese de Aarão Reis sobre os relatórios evidenciam o cuidado metodológico sobre os itens a serem avaliados. No que tange ao item "esgoto", Reis constrói uma argumentação baseada em autores que Ihes são bem contemporâneos (citando até mesmo um estudo francês de 1892), mostrando intimidade com a temática. Para ele, essa nova capital deve ser, antes de tudo, moderna, uma cidade do futuro. Seria impensável a prática do tout-à-la-rue, ou seja, as imundícias sendo lançadas nas ruas e calçadas da Cidade de Minas, mesmo esta tendo uma certa

\footnotetext{
"Este "sacrifício" foi reconhecido por Aarão Reis meses mais tarde no Relatório da Commissão d'Estudo...
} (MINAS GERAES, 1893). 
inspiração francesa (SALGUEIRO, 1995). Segundo Aarão Reis, tão fundamental quanto suprir a cidade das melhores águas para consumo, era que esse volume d'água, depois de utilizado pela população, encontrasse "fácil e prompta evacuação, que a leve, com as impurezas que acarreta, para fora da cidade" (MINAS GERAES, 1893, p.55). Logo em seguida, ele escreve sobre o cuidado do transporte (adução) do esgoto para que ele não fique estagnado em algum ponto do caminho e traga doenças. Isso aponta para a possibilidade de que Aarão Reis já compartilhava da ideia da circulação constante das águas sujas para a prevenção de doenças.

Em comparação a outras cidades, e até mesmo aos engenheiros de sua comissão, Reis parece tomar na elaboração do projeto uma posição um pouco diferenciada quanto à importância da dimensão da coleta/adução (saneamento interno) e da dimensão de destinação/tratamento (saneamento externo), enfatizando uma maior discussão sobre essa última dimensão. Para ele, a decisão pela melhor tecnologia de saneamento interno estava claro: tout-à-l'égout. Ele afirma que haviam sido preconizados vários sistemas de esgotamento, mas que, para ele

Entre os systemas de esgôto, avantaja-se o de - TUDO AO ESGOTO - em que todas as aguas servidas, de qualquer natureza que sejam, e, bem assim, todas as matérias que ellas possam acarretar, são reunidas em colletoresprincipaes que as evacuam para fora da cidade. (MINAS GERAES, 1893, p.56)

Faltaria então deter-se um pouco mais e debater sobre o saneamento externo: o que fazer com os materiais e líquidos coletados? O engenheiro argumenta que opta

Pelo desaparecimento das [águas] d'esgôto despejadas, depois de conveniente desinfecção, n'um rio caudaloso, ou no mar, ou então, pela respectiva epuração pela absorpção pelas terras aplicadas, ou não, ao cultivo. (MINAS GERAES, 1893, p.56)

Aarão Reis é um otimista quanto às técnicas e métodos de destinação dos esgotos, principalmente no que tange à utilização agrícola do mesmo, ao apontar que "conceituados higienistas" europeus atestam "as vantagens que usufruem a agricultura da utilização de tão precioso fertilisante" (MINAS GERAES, 1893, p.56). Afirma ainda que a (d)epuração do esgoto pela absorção das terras cultiváveis é incontestavelmente o "melhor e mais completo" dos processos práticos de destinação (p. 56). Para reiterar essa opção, ele realiza cálculos e afirma que seria necessário, 
para depurar o volume de esgoto produzidos por 200 mil habitantes ${ }^{7}$ "dispor, nas cercanias, de 2200 hectares de terras cultiváveis, ou pelo menos, de 110 hectares próprios para a epuração simples". Apenas a título de ilustração, tomando como medida um quarteirão projetado no Plano da Cidade de Minas (Belo Horizonte), que possui aproximadamente 1 hectare $(100 \mathrm{~m} \times 100 \mathrm{~m})$, seria necessário uma área equivalente a no mínimo 110 quarteirões da cidade planejada para a realização de uma "epuração simples", ou uma área no mínimo três a quatro vezes maiores do que a cidade planejada, para a obtenção terras cultiváveis.

Essa possibilidade de destino sanitário era então ao mesmo tempo interessante - tendo em vista os progressos e os ganhos para a vida urbana a partir do uso dos esgotos como fertilizantes de baixíssimo custo e grande quantidade - e inviável - tendo em vista as condições topográficas e pedológicas das localidades estudadas. Essa lamentável realidade local força Aarão Reis a olhar as extensas áreas de depuração do projeto parisiense (mostrado na Fig.1 acima) e concordar com o engenheiro francêsPignant, que afirmava ser "necessário terras". Logo conclui:"Ora, em nem uma das localidades estudadas [...] há área suficiente e menos configuração topográfica apropriada para a adoção deste systema aperfeiçoado de epuração pelas terras." (MINAS GERAES, 1893, p.56)

Contudo, a proposta de saneamento externo de Aarão Reis não estava de todo perdido, pois ele afirmava, mais uma vez amparado em estudiosos da área, que em cada uma dessas localidadeshavia um "rio caudaloso que recebe e epura, pela agitação, as matérias sólidas" (MINAS GERAES, 1893, p.57). E vai além, ao dizer "nem há hygienista que - ainda mesmo preferindo, como é natural, o primeiro systema - conteste que este outro pode e deve substituí-lo em muitos casos" (MINAS GERAES, 1893, p.57), sendo esse "primeiro systema" o sistema de depuração pelo solo. Nesse momento Reis vai compartilhar da tese que afirmava, na época, que a agua de esgoto que carregava os excrementos humanos e outros dejetos poderia ser purificada através da grande agitação e do turbilhonamento fluvial. Do autor francês Arnold, "autoridade da maior competência", o engenheiro-chefe retira as palavras: lefleuve se purifielui-meme ${ }^{8}$ (MINAS GERAES, 1893, p.57). Assim, as localidades deveriam ter um curso d'água (rio ou ribeirão) que não fosse apenas grande, mas que possuísse a jusante, "corredeiras e cachoeiras" para depuração por "dissolução forçada". Mas, lembra Aarão Reis, antes de serem lançadas à jusante (ou seja, no fim

\footnotetext{
${ }^{7}$ Que seria em torno de 22 milhões de $\mathrm{m}^{3} / \mathrm{ano}$, tendo como base o consumo individual de 300 litros d'água/dia.

8 "O rio purifica-se a si mesmo", em uma tradução livre.
} 
dos grandes coletores principais/gerais), deveria se ter "o cuidado de estabelecer a desinfecção prévia d'essas aguas, por meio dos maios aperfeiçoados processos chimicos, antes de lançal-as no rio" (MINAS GERAES, 1893, p.57).

E, por todas essas avaliações e ponderações, o chefe da Comissão decide por escolher, no quesito Saneamento Interno e Externo, Várzea do Marçal, que possuía o Rio das Mortes (que desagua no grande Rio Carandaí), como a melhor localidade para sede do Estado. Em segundo lugar seria escolhida Paraúna, por conta do Rio Paraúna, e apenas em terceiro lugar viria "BelloHorisonte", com seu ribeirão Arrudas.

Antes de dar prosseguimento sobre os debates que definiriam a escolha da localidade, é importante um pequeno aprofundamento a respeito do relatório confeccionado por Samuel Pereira, engenheiro encarregado por Aarão Reis a estudar a localidade de "BelloHorisonte".

É notável a discordância de Samuel Pereira sobre as tecnologias de sistemas de esgotos possíveis (principalmente referente ao saneamento interno) à luz dos debates sanitaristas e higienistas da época e frente às condições do terreno belohorizontino. Samuel primeiramente argumenta sobre o excelente ribeirão Arrudas, e as possibilidades advindas dele. Defende que na localidade de BelloHorisonte possui "água em abundância" e que não se teria problemas para adução dos esgotos para fora da cidade (aliás, um dos critérios importantes para a futura capital é que ela tivesse cursos d'agua tanto para abastecer a cidade quanto para levar dela as sujeiras).

Quando começa a argumentar sobre os sistemas de esgoto, inicia falando dovindage à l'égout(despejos no esgoto), um sistema de esgotamento externo correspondente à tecnologia (já apresentada acima) de depuração pelo solo. Samuel afirma que, ao contrário das terras planas e arenosas ao norte de Paris / baixo Seine (apresentadas na Fig. 1 acima), a bacia do córrego Cardoso é estreita e sem planícies que prestem para tal propósito, além da pouca permeabilidade do solo e forte declividade.

Mais a frente, em um posicionamento oposto ao de Aarão Reis, argumenta contra o tout-à-l'égout ao dizer que vários autores (ressalte-se, de língua inglesa) contestam tal sistema, pois o mesmo sofre objeção em "qualquer que seja a localidade onde fôrapplicado" e é "questão resolvida teoricamente por autoridades" do assunto (MINAS GERAES, 1893, p.17). Além disso, Samuel Pereira afirma que esse sistema é desvantajoso por necessitar de "um colletor geral de grande secção ( $2 \mathrm{~m}$ de diâmetro) e de muitos kilometros de comprimento" (MINAS GERAES, 1893, p.17). 
Outro sistema apresentado pelo autor seria o proposto pela supracitada Comissão de Saneamento de Paris (1880), que, segundo ele, teria condições de se estabelecer em um terreno como o belo-horizontino. Nesse sistema, conforme ressalta o autor, os despejos seriam canalizados por tubos metálicos e levados para usinas (oficinas) instaladas longe da cidade, onde o esgoto seria transformado.

Parecendo optar pela tecnologia do Sistema Separador, desenvolvido por George Waring, o engenheiro Samuel tece uma argumentação mais explicativa do que crítica, ressaltando as vantagens dessa tecnologia que realizava a "separação dos despejos das casas particulares e matérias fecaes, das matérias do exgotto proveniente de vias públicas e das aguas pluviaes": gera menos dispêndios ao dispensar a construção de grandes coletores (de $2 \mathrm{~m}$ de diâmetro ou mais); apresenta "solidez e permeabilidade"; possibilita constantes lavagens; e diminui o "perigo de emanações provenientes de materiasfecaes e aguas servidas" (MINAS GERAES, 1893, p.17). Para sacramentar sua opção pelo sistema Waring e rejeitar de fato a possibilidade de um sistema tão "descontextualizado" à realidade local como era o tout-à-l'égout, Samuel usa do poder discursivo existente nas "falas de autoridades estrangeiras" e escreve:

O StateBoardof Health, reunido em New York, depois de acurados e conscienciosos estudos feitos pelos seus mais distinctos membros, engenheiros e higyenistas, especialistas neste ramo da sciencia moderna, votou as seguintes conclusões: o sistema dispendioso de despejos para o exgotto (tout à l'égout), exigindo o emprego de conductos de grande secção, foi reconhecido, tanto na Inglaterra como na América [EUA] como um desacerto sanitário; ao passo que o systema separador de Waring, bem applicado, apresenta em pequena proporção os perigos, hoje tão geralmente observados, dos gazes dos exgottos e é menos dispendioso para a maior parte das cidades. (MINAS GERAES, 1893, p.18).

Depois dessa defesa do sistema Waring, o engenheiro Samuel Gomes apresentaria mais duas tecnologias em sistemas de esgotamento: a desenvolvida pelo engenheiro Liernur, também chamado de Sistema Diferenciador, e o Sistema Berlier. O Sistema Diferenciador é composto de duas redes de encanamentos: "uma para a evacuação das aguas pluviaes, das aguas servidas e dos resíduos da indústria, e outra, a rede pneumática para evacuação das matérias fecaes" (MINAS GERAES, 1893, p.18). Essa tecnologia possuiria grandes vantagens econômicas frente ao Sistema Unitário e Separador, mas só é realmente vantajoso em terrenos com pouca declividade (o que não seria o caso de Belo Horizonte). Por sua vez, o Sistema Berlier, apesar de poder ser aplicado na localidade estudada, seria engenhoso e complicado, 
não apresentando vantagens econômicas, embora utilize as matérias fecaes para o processo produtivo de adubo e sais amoníacos. Essa produção só poderia ser feita com dejetos secos e frescos, tal qual aqueles retirados pelos limpa-fossas na França, pois assim não fermentam e não perdem a "riqueza em azoto".

Ao concluir o estudo sobre as possibilidades de esgotamento no antigo Curral d'El Rey, Samuel reitera que os quatro sistemas apoiados por ele (Sistema Separador, Sistema Diferenciador, Sistema Berlier, e o sistema proposto pela Comissão de Saneamento de Paris de 1880) poderiam ser aplicados em Belo Horizonte, "competindo à comissão dos estudos definitivos dar preferencia a um delles" (MINAS GERAES, 1893, p.18). A riqueza desses relatórios é que eles evidenciam disputas teóricas de tecnologias concretas e possíveis. Como foi apresentado, dois grandes engenheiros, estudantes da mesma escola de engenharia (Politechnicado Rio de Janeiro), amigos de profissão e de vida, serão dissonantes quanto à opinião sobre o tout-à-l'égout.

Retornando a Aarão Reis e suas ponderações sobre as localidades candidatas à capital do Estado, constata-se no Relatório que Várzea do Marçal não era apenas a melhor no item saneamento, mas também na síntese avaliativa final, ficando Belo Horizonte com a segunda colocação geral. O engenheiro-chefe então entrega 0 relatório em 1893 para o Governo de Minas Gerais e espera que os estudos sejam apreciados pelos políticos em sua tomada de decisão a respeito da localidade. Todavia, justamente as debilidades de Belo Horizonte em alguns itens, na comparação com Várzea Marçal, fazem com que os políticos antimudancistas de Ouro Preto optem pelo antigo Curral d'El Rey, em detrimento da localidade são-joanense vencedor tecnicamente. Os ouro-pretanos esperavam que o prazo curto para a conclusão das obras e as dificuldades de transporte (ferrovias) por um lado, e as melhoras no tecido urbano de Ouro Preto (como as propostas de sistematização dos esgotos apontados no início deste texto), fizessem com que os políticos mineiros revertessem a mudança (FUNDAÇÃO JOÃO PINHEIRO, 1996)

Entre 1893 e1894 desfaz-se a Comissão de Estudos e cria-se a Comissão Construtora da Nova Capital (CCNC), tendo à frente o mesmo chefe da derradeira comissão, Aarão Reis. Ele conservou também alguns engenheiros nessa nova empreitada, e convidou outros nomes, como Saturnino de Brito (posteriormente considerado o patrono da Engenharia Sanitária Brasileira). Durante a chefia de Aarão Reis, entre 1894 e 1895, pouca coisa fora feita no que tange à implementação de um sistema de esgotamento sanitário. De acordo com Saturnino de Brito (1944 [1895]), durante todo o ano de 1894 a seção de esgoto e subsolo "esteve acéfala e apenas fez, 
sem método e sem proveito, uns poços de sondagem" (p. 33). Ainda afirma o autor que houvera uma linha de exploração na margem direita do ribeirão Arrudas que "sendo forte a declividade do ribeirão, cedo afastou-se e disparou a contornar grotas e espigões na extensão de cerca de sete quilômetros" (BRITO, 1944, p.34). Ao perguntar o que se ia fazer com essa linha de exploração, Saturnino de Brito recebeu uma resposta dos "entendidos": "procurar um campo para o lançamento dos produtos de esgoto" (BRITO, 1944, p. 34). Ao que tudo indica, Aarão Reis ainda continuava com a ideia de criar um campo de depuração de esgotos, mesmo que, conforme projetou em sua Planta, fosse ínfima em relação à medida necessária (Fig. 2 e 3).

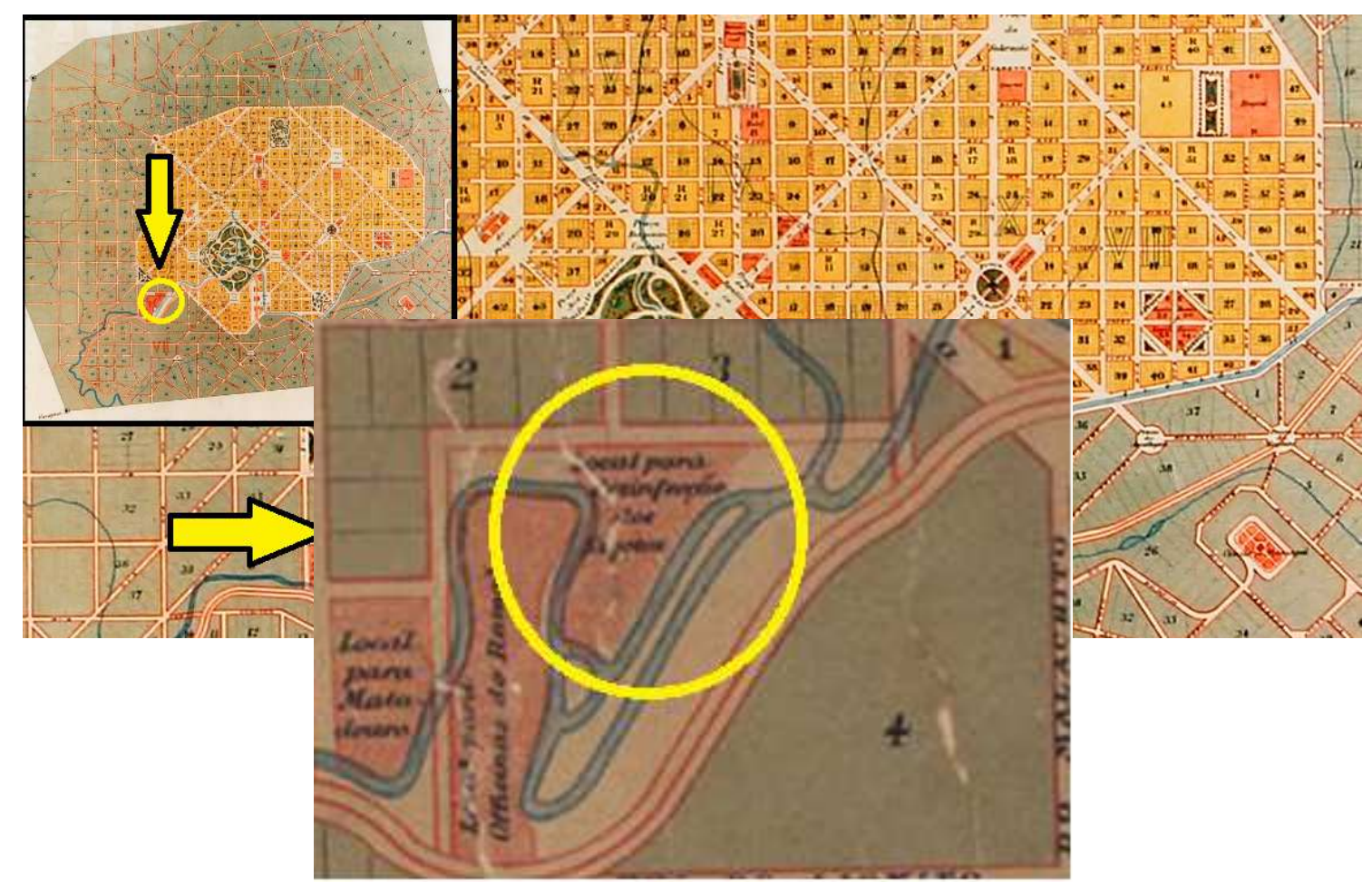

Figura 02 - Parte da Planta Topográfica e Cadastral da Cidade de Minas, com indicações da área destinada pelo projeto de Aarão Reis para a depuração de esgotos, localizada à margem direita do ribeirão Arrudas

Fonte: Montagem realizada a partir do mapa encontrado em MINAS GERAES, 1895a.

Figura03 - Detalhe da Planta Topográfica e Cadastral da Cidade de Minas, com destaque para onde se lê: Local para desinfecção dos Exgottos. Apenas a título de localização, esse terreno está sob o atual Boulevard Shopping, no bairro de Santa Efigênia, Belo Horizonte.

Fonte: Belo Horizonte: MINAS GERAES, 1895a

O último comentário feito por Brito em seu relatório explicativo escrito em 1895 (e publicado em livro em 1944) foi a respeito do que ele considerou o "único serviço apresentado" de fato pela inoperante $2^{a}$ seção (dos esgotos) da $5^{a}$ divisão (de águas e esgotos e subsolo) da CCNC: o anteprojeto da rede de esgotos; e isso "deve- 
se à atitude enérgica do Sr. engenheiro Aarão Reis, desejoso de deixar alguma coisa feita sobre o assunto, antes de sair da Comissão" (BRITO, 1944, p. 34). Importante notar o fato de que esse anteprojeto revela a preferência pelo sistema Waring, defendidoanteriormente por Samuel Pereira, em detrimento da escolha de Aarão pelo tout-à-l'égout. Segundo o anteprojeto:

O sistema que adotamos com a vossa aprovação - o sistema Waring - parece o mais apropriado às circunstâncias locais. Os mesmos adversários de tal sistema, pela capacidade restrita dos encanamentos, reconheceram a perfeita conveniência a pequenas povoações. Ora, a nossa cidade está pela natureza dividida em distritos separados na configuração e relevo do solo e pode ser considerada por esse lado como pequenos núcleos de povoação justapostos. Uni-los, a não ser por um coletor geral no vale principal, sim, pediria meios menos singelos, da parte de um projeto de esgoto, com sacrifícios da economia. (FUNDAÇÃO JOÃO PINHEIRO, 1996, p. 32)

Semanas depois, Aarão Reis é exonerado do cargo, assumindo em seu lugar o engenheiro Francisco Bicalho. Com uma gestão mais empreendedora que Aarão Reis (FUNDAÇÃO JOÃO PINHEIRO, 1996, p. 32), é Bicalho que concretiza - mesmo que precariamente - boa parte do plano e das ideias de Aarão. Reorganizando a CCNC, 0 novo Engenheiro-chefe cria uma divisão exclusiva para esgotos - 9a Divisão -sob os auspícios do engenheiro Ludgero Dolabela. Durante o ano de 1895, Bicalho vai gerenciar a construção da capital priorizando o fornecimento e transporte de materiais e equipamentos, a mão de obra e a formação de uma mínima rede de serviços para a ocupação inicial de 30 mil habitantes. No que se refere aos esgotos, ele irá tecer "longas considerações acerva do projeto da rede de esgotos da Nova Capital" (FUNDAÇÃO JOÃO PINHEIRO, 1996, p. 35), rejeitando a opção da antiga 2a Seção pelo Sistema Waringe pendendo a favor do tout-à-l'égout. Em um relatório de abril de 1896, Francisco Bicalho vai afirmar que:

[...] trata-se de uma grande cidade [...] deve ser edificada com todos os melhoramentos[...]. Impunha-se, pois, o tout à l'égout, reconhecido hoje pelas principais autoridades sobre o assunto como o mais aperfeiçoado sistema, que tem indiscutíveis vantagens sobre qualquer outro, principalmente aliado à depuração das águas dos esgotos por meio da infiltração no solo, que constitui hoje a medida mais eficaz e garantidora da salubridade e boa higiene"(FUNDAÇÃO JOÃO PINHEIRO, 1996, p. 35-6)

Nota-se que para Bicalho o tout-à-l'égout abrange tanto o sistema de esgotamento interno - Sistema Unitário - quanto o sistema de esgotamento externo sistema de depuração pelo solo. Para o engenheiro-chefe, esse híbrido sistema 
interno-externo é o mais aperfeiçoado, reconhecido pelas "principais autoridades sobre o assunto". Também fazendo uso do peso da "fala das autoridades" para corroborar seu discurso, tal qual fizeram os defensores do Sistema Waring, Francisco Bicalho mostra como certos conhecimentos técnico-científicos vão sendo constituintes (e constituídos) de políticas de intervenção na realidade urbana. É mister lembrar aqui que em julho de 1894 a cidade de Paris havia adotado oficialmente (e obrigatoriamente) o princípio do tout-à-l'égout, não sem muita argumentação teórica sobre o assunto, o que produzira uma farta documentação a favor desse sistema. Esse fato que não pode ser desprezado quando se busca compreender as elaborações de projetos políticos, de engenharia e urbanísticos do fin-de-siècle brasileiro, já que eles estão em constante diálogo.

Essa retomada por Bicalho do tout-à-l'égoutmeses depois da reprovação desse sistema poderia revelar um jogo de interesses econômicos, onde empreiteiras e políticos estivessem envolvidos? Não é possível afirmar ao certo. Mas sabe-se que a construção do Sistema Unitário durante os anos seguintes foi dissociada da concretização de um sistema de esgotamento externo.

No documento Informações sobre os serviços executados pela extinta Comissão Construtora de $1^{0}$ de Janeiro a 31 de dezembro de 1897constam-se as informações de que até dezembro de 1897, foram construídos 55\% dos coletores (provavelmente primários) de alvenaria de tijolos previstos no projeto (o maior desses coletores tinha 2,7 metros de altura por $1,6 \mathrm{~m}$ de abertura); e assentadas apenas 3290 metros de manilhas (dos coletores secundários) das 80 mil que estavam previstas (FUNDAÇÃO JOÃO PINHEIRO, 1996, p. 37). Ainda segundo a pesquisa da Fundação João Pinheiro (1996, p.40), "não se teve acesso, entre os acervos documentais da Comissão Construtora, a nenhum mapeamento [...] da primeira rede de esgotos". Essa rede deveria ser formada pelos coletores secundários (ligados às edificações) que são conectados aos coletores-tronco (primários), que por sua vez desaguam nos Interceptores, que, finalmente, são conectados aos Emissários, que transportam as águas esgotadas para um sistema de tratamento apropriado. Até a sua inauguração, a "Cidade de Minas" (nome oficial de BeloHorizonte à época) havia construído apenas um emissário entre a Estação Ferroviária e o Parque Municipal, canalizado pequenos trechos de córregos e deixado a implementação de uma estação de tratamento de esgotos só para os fins do século XX. Antes mesmo de ser inaugurada, a capital já lançava seus esgotos sem tratamentos nos córregos e no ribeirão Arrudas, mesmo contra os cuidados salubristas e higiênicos. Como bem afirma o texto da Fundação João Pinheiro (1996, p. 41), "questões materiais 
colocavam por terra preceitos sanitaristas fundamentais, tão propaladas pelos projetistas".

Outras obras de saneamento pararam desde esse último ano da Comissão, como aponta Bernardo Monteiro, o quinto prefeito a governar a cidade (RELATÓRIOS, 1899-1902). Monteiro irá lidar com uma pequena cidade em termos populacionais (na época a população era de aproximadamente 25 mil habitantes), mas grande em termos de importância político-administrativa. Os relatórios apresentados por esse prefeito serão fundamentais para uma melhor compreensão das mudanças que foram sendo adotadas tendo em vista a substituição do Sistema Unitário pelo Sistema Separador.

No primeiro Relatório (1899-1900), Monteiro já alertava para as insuficiências do Sistema Unitário face às chuvas torrenciais, que provocavam fortes enxurradas que não poderiam "ser recolhidas pelas redes de esgoto" (RELATORIO, 1899-1900, p.30), e defendia a construção "incontestável" de um "canal de contorno" para conter as enxurradas, o que seria uma alteração no projeto do tout-à-l'égout. Vale ressaltar aqui um importante detalhe. A sua adoção por cidades tropicais, como Belo Horizonte, já era criticada por vários engenheiros muito antes das escolhas das localidades. 0 sistema Waring, projetado para cidades americanas que possuíam grandes épocas de chuvas, foi adaptado e adotado em várias cidades brasileiras. Saturnino de Brito defendeu o sistema tout-à-l'égout até seus trabalhos em Santos (ou seja, quando trabalhava em Belo Horizonte, ainda defendia esse sistema, "situando-se junto aosengenheiros de Ponts-et-Chaussées", conforme aponta ANDRADE [1992, p. 80]). Durante sua estadia nessa cidade paulista, "reconhecendo a ineficiência desse sistema para cidades cujo clima tivesse elevados índices pluviométricos, o que implicaria superdimensionamento das tubulações [que já eram grandes], Brito optou pelo sistema separativo [separador]" (ANDRADE, 1992, p.81). Essa constatação de Brito seria realizada por Bernardo Monteiro anos antes, também através da observação e da prática urbanas, no reconhecimento das impossibilidades existentes naquele modelo de Sistema Unitário implantado (parcialmente) em Belo Horizonte, e na observação diárias das torrentes chuvas que insistiam em cobrir certos pontos da cidade. 


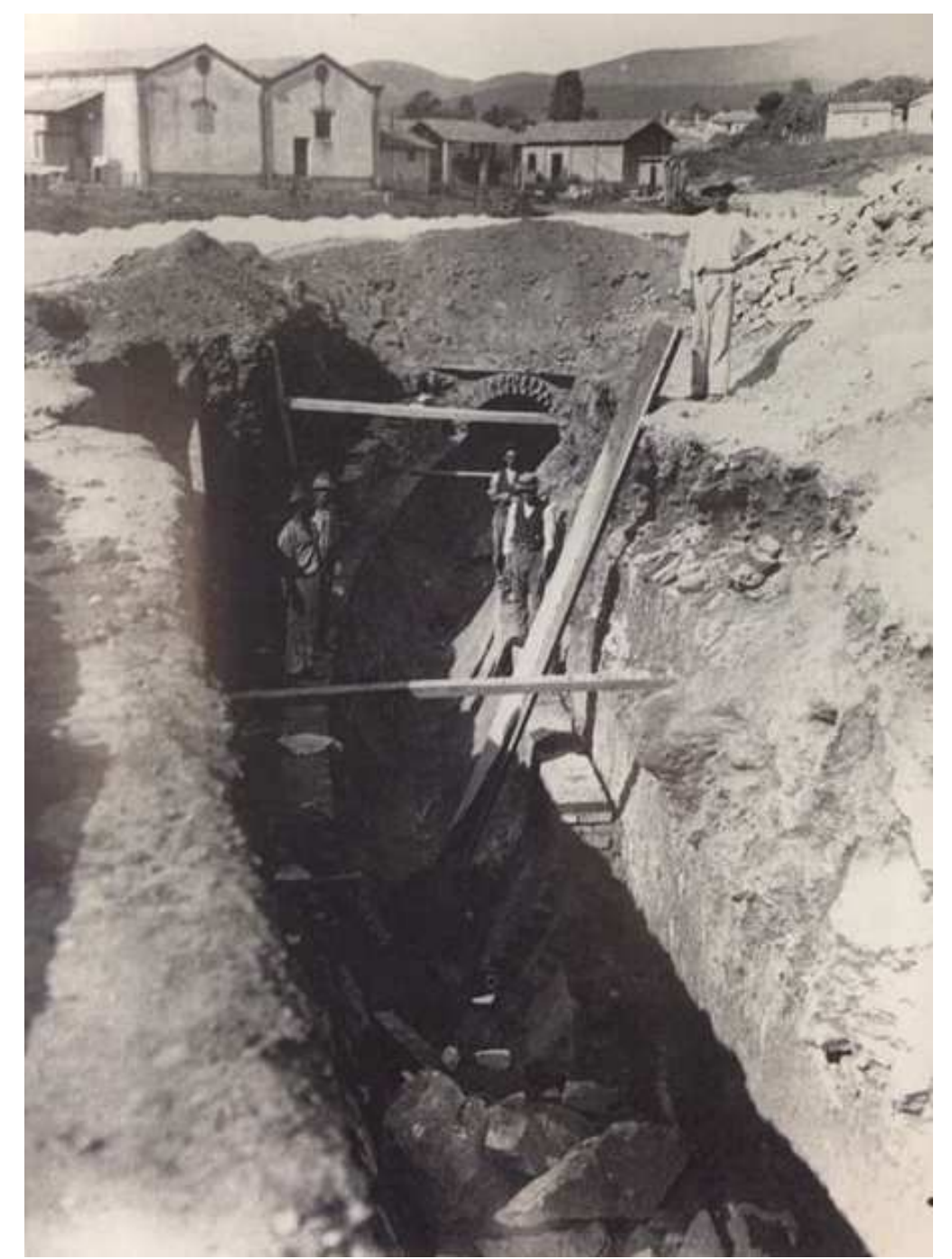

Figura 04 - Um emissário de esgotos no início do século XX em Belo Horizonte.

Fonte: Belo Horizonte: Arquivo Público Mineiro, s/d

Contrariando o tout-à-l'égout, a primeira intervenção na rede original foi uma galeria pluvial na Rua da Bahia, para solucionar provisoriamente o grave problema das inundações no centro da recém-inaugurada Capital (FUNDAÇÃO JOÃO PINHEIRO, 1996, p. 42). Em seu segundo Relatório (1899-1902), Bernardo Monteiro aponta que "não foi calculada para nossa rede a quantidade de chuva" (p. 112) que ocorria naquele momento na cidade planejada9 ${ }^{9}$. Já em outro trecho do relatório, o prefeito revela uma clara cisão da proposta do Sistema Unitário, e o emprego de técnicas e ações para compor "informalmente" um proto-sistema Separador:

\footnotetext{
${ }^{9}$ Contudo, os estudos feitos quase uma década antes descrevem vários dados sobre a geografia local, inclusive índices pluviométricos (MINAS GERAES, 1893). 
Uma vez construída a rede para águas coaclaes e servidas podemos agora [...] cuidar do assentamento de algumas linhas complementares, nos trechos em que a canalização é dupla, linhas que devem receber as aguas da chuva e, de futuro, com o aumento das construcções virão servir para exgottos particulares. (RELATÓRIO 1899-1902, p. 118)

Conforme aponta o estudo da Fundação João Pinheiro (1996, p. 42), "em 1902, já se constatava que o funcionamento dos esgotos pelo Sistema tout à l'égout não respondia às necessidades de escoamento das águas pluviais". Nas páginas subsequentes do seu relatório, o prefeito ainda irátecer formais elogios ao Sistema Unitário, sem deixar de atentar-se para os problemas que emergiam na realidade local, dizendo que

embora a nossa bela cidade já apresente magnifica rêde de exgottos, construída para o tout à legout, composta de grandes coletores de alvenaria de tijolos e cimento, dos quaes os maiores tem a altura $2 \mathrm{~m} 07$ por $1 \mathrm{~m} 60$ de largura $[\ldots]$, muito entretanto nos resta fazer. (RELATÓRIO, 1899-1902, p.121).

Para o prefeito, o grande problema a se resolver era o costumeiro hábito de habitantes e governantes de lançar, nos cursos d'água, o líquido esgotado sem nenhum cuidado. Se os primeiros planejadores, de Aarão Reis a Saturnino de Brito, atentos que estavam às discussões ultramar sobre a limpeza e a despoluição dos cursos d'água urbanos (como o caso do rio Seine em Paris do fim dos Oitocentos), pensaram no saneamento externo - ou seja, propuseram possibilidades de depuração, tratamento e uso dos esgotos coletados- o mesmo ideal não vai permanecer nos anos seguintes da construção desse ambiente urbano, agravando em pouco tempo as condições objetivas de qualidade do ribeirão Arrudas. Para o prefeito Bernardo Monteiro, os emissários do esgotamento não poderiam lançar suas águas no Arrudas por muito tempo, pois mesmo esse curso apresentando cachoeiras, apresenta também trechos de pequena declividade onde se poderia acumular esgoto (RELATORIO, 1899-1902, p. 121). Logo, a construção de filtros se torna importante no tratamento do esgoto, ao mesmo tempo em que se lança o olhar interessado ao campo de depuração: "o tratamento pela filtração natural nos campos de cultura, si bem que apresente dificuldades a sua installação, todavia não será impossível consegui-la" (RELATORIO, 1899-1902, p. 121).

Será questão de tempo para que, se assuma, oficialmente, a adoção por parte da prefeitura do antigo Curral d'El Rey, da tecnologia do Sistema Separador misto, um grande híbrido de possibilidades sanitárias. O prefeito sucessor de Monteiro, Francisco 
Bressane, vai relatar o lamentável fato de os coletores (que não foram ligados ao coletor principal) ainda jogarem "esgoto no ribeirão, mesmo antes de [o ribeirão] passar na cidade" (RELATORIO, 1902-1903, p. 28), prejudicando todo um caminho desenrolado por esse curso hidrográfico ao longo da faixa norte do Plano. Bressane ainda parece desnorteado ao dizer que "é questão de capital importância o destino das águas dos principaes emissários" (RELATORIO, 1902-1903, p. 29), como se não houvesse inúmeros projetos e possibilidades técnicas sobre o onde/como/o que fazer com o esgoto belo-horizontino, desde Samuel Pereira. Mas, há um ponto em que tanto Brescianne, Monteiro, Brito, Reis, Bicalho, Samuel e tantos outros concordarão: é no chão das tecnologias do saneamento básico onde"fundam-se as garantias da salubridade futura" (RELATORIO, 1905, p. 40).

\section{Considerações Finais}

Se durante o séc. XIX observa-se a discussão sobre a viabilidade ou não de sistemas de esgotos que abranjam a coletividade urbana, as duas últimas décadas do século XIX tomam os sistemas de esgotamento como um imperativo. O debate aí então passa a ser qual o melhor sistema a se adotar. A tecnologia empregada em cada um dos sistemas irá variar conforme o uso dos materiais utilizados, a extensão do terreno e os aspectos geográficos da localidade, entre outros fatores (como a quantidade de recursos disponíveis para tal empreitada). Cada modelo de sistema de esgotamento tinha seus prós e contra, podendo ser agrupados em três categorias principais: o sistema unitário, o sistema separador parcial (ou misto) e o sistema separador absoluto. O sistema unitário ficou conhecido no Brasil como tout-a-l'égout, termo francês que designa "tudo ao esgoto". Já o sistema separador absoluto ficou conhecido como Waring. A escolha do tout-a-l'égout- tudo ao esgoto - feita para Belo Horizonte, em poucos anos demonstraria falhas a ponto de ser substituído.

Provavelmente a primeira capital do mundo a nascer com um projeto para a implementação de um sistema de saneamento, a Nova Capital mineira experimenta desde os primeiros passos as complexidades de um "devir-urbano". Entre teoria e prática existirão abismos, e a história (sobretudo a de Belo Horizonte) está aí para comprovar ou desmentir tal afirmativa. A cidade planejada é ela mesma outra cidade, como o modelo celestial da Bersabéia descrito por Ítalo Calvino em As cidades invisíveis, onde gravitariam os sentimentos mais elevados de uma cidade. Para um antigo morador do Curral d'El Rey, "na época em que se deu a mudança da Capital, Belo Horizonte era um traçado na gaveta de Aarão reis e sonho lindo na mente do 
povo mineiro" ${ }^{10}$. Parece que, até hoje, a cidade terrena de Belo Horizonte ainda não encontrou a cidade projetada pelos Fundadores da Cidade de Minas.

\section{Referências}

ANDRADE, C.R.M. (1992). "A Cidade como um Corpo São e Belo: o pensamento. urbanístico do engenheiro Saturnino de Brito" in FERNANDES, A., G. M.A.A.F. Cidade \& História. Modernização das Cidades Brasileiras nos séculos XIX e XX. Salvador: Mestrado em Arquitetura e Urbanismo.

ANDRADE, W. C. P. ; OLIVEIRA, D. J (2012). Carroceiros em Belo Horizonte: ruralidade na metrópole? In: I Seminário Internacional Cidade e alteridade: convivência multicultural e justiça urbana, 2012, Belo Horizonte. Anais do I Seminário Internacional Cidade e alteridade: convivência multicultural e justiça urbana.

BARRETO, A (1936). Belo Horizonte: memória histórica e descritiva; história antiga e história média. 2 ed. Belo Horizonte: Fundação João Pinheiro, Centro de Estudos Históricos e Culturais, 1996. 2 v, 447 p. e 916 p. Publicado originalmente em 1928 ( $v$. 1) e (v. 2).

BECHMANN, G (1899). Salubritéurbaine, distribuitionsd'eauetassainissement. Paris: LibrairiePolitechnique. Disponível em: http://gallica.bnf.fr/ark:/12148/ bpt6k91017s. Acesso em: 28 jun. 2013.

BRITO, F. R. S (1944). Obras completas. Vol. XVIII - Memórias Diversas. Rio de Janeiro: Imprensa Nacional.

CASTRO, M.L.A.C.; AMARO, J.J.V (2007). Implantação do sistema de saneamento em Ouro Preto no século XIX: a disputa pela Capital [on-line] In: Os Urbanitas Revista de Antropologia Urbana. Ano 4, vol.4, n.5 Disponível em http://www.osurbanitas.org/osurbanitas5/Castro\&Amaro2007.html. Acesso em 25 jun. 2013

CORBIN, A (1987). Saberes e Odores: o olfato e o imaginário social nos séculos XVIII e XIX. São Paulo: Companhia das Letras.

FUNDAÇÃO JOÃO PINHEIRO (1996). Centro e Estudos Históricos e Culturais. Saneamento básico em Belo Horizonte: Trajetória em 100 anos - os serviços de água e esgoto. V.3, Belo Horizonte.

LEMOS, F.L.C; CARDOSO JUNIOR, H.R (2009). A genealogia em Foucault: uma trajetória. Psicologia e Sociedade, p. 353-357, v. 21, n. 3.

MEDEIROS, J.A.; MEDEIROS, L.A (1993). O que é tecnologia. São Paulo: Brasiliense.

${ }^{10}$ FUNDAÇÃO JOÃO PINHEIRO, 1996, p. 39.

URBANA, V.6, no 8, jun.2014 - Dossiê: Cidade e Habitação na América Latina - CIEC/UNICAMP 
RESENDE, S. C.; HELLER, L (2008). O Saneamento no Brasil: Políticas e interfaces. 2a. Edição, Belo Horizonte, Editora UFMG.

SAlgueiro, H. A (1997). Engenheiro Aarão Reis: o progresso como missão. Belo Horizonte: Fundação João Pinheiro, Centro de Estudos Históricos e Culturais, 288 p. SAlgueiro, H. A (1995). Revisando Hausmann. Revista USP. São Paulo, no 26, pp. 195-205.

\section{Fontes}

MINAS GERAES (1893). Commissão d'Estudo das Localidades Indicadas para a nova Capital. Relatorio apresentado a S. Ex. Sr. Dr. Affonso Penna, Presidente do Estado, pelo engenheiro civil Aarão Reis. Rio de Janeiro: Imprensa Nacional. Acervo MHAB.

MINAS GERAES (1895a). Commissão Constructora da Nova Capital. Planta Topographica e Cadastral da área destinada à Cidade de Minas. Belo Horizonte. Escala 1/4000. 240 x $180 \mathrm{~cm}$. Acervo Arquivo Público da Cidade de Belo Horizonte - APCBH. MINAS GERAES (1895b). Commissão Constructora da Nova Capital. Planta Geral da Cidade de Minas. Belo Horizonte. Escala 1/4000. 245 x 130cm. Acervo APCBH. RELATÓRIOSanuais apresentados pelos prefeitos (1899-1905). Relatório. Belo Horizonte: Imprensa Oficial do Estado de Minas Gerais. 